\title{
HUBUNGAN PENGETAHUAN DAN SIKAP WANITA USIA SUBUR (WUS) DENGAN PEMAKAIAN ALAT KONTRASEPSI
}

\author{
Nirma Lidia Sari \\ Akademi Kebidanan Panca Bhakti Bandar Lampung \\ E-mail: lidianirma@gmail.com
}

\begin{abstract}
ABSTRAK
Pencegahan kematian dan kesakitan ibu merupakan alasan utama diperlukannya pelayanan Keluarga Berencana (KB). Program KB bertujuan untuk memenuhi keperluan masyarkat akan pelayanan KB dan kesehatan reproduksi dalam rangka membengun keluarga kecil berkualitas. Tujuan penelitian ini yaitu untuk mengetahui hubungan antara pengetahuan dan sikap Wanita Usia Subur (WUS) dengan pemakaian alat kontrasepsi.Metode penelitian ini bersifat deskriptif korelational dengan pendekatan cross sectional, data yang digunakan adalah data primer yang dikumpulkan dengan menggunakan kuesioner kepada 100 wanita usia subur dengan teknik pengambilan sampel proportional random sampling. Data diolah dengan menggunakan program software komputer dan dianalisis menggunakan uji chi square, kemudian disajikan dalam bentuk distribusi frekuensi. Hasil penelitian ini yaitu pengetahuan wanita usia subur tentang alat kontrasepsi yang termasuk dalam kategori kurang (12\%), sikap wanita usia subur terhadap alat kontrasepsi yang termasuk dalam kategori negatif (43\%), dan wanita usia subur yang tidak memakai alat kontrasepsi sebanyak (17 $\%)$. Antara pengetahuan Wanita Usia Subur (WUS) dengan pemakaian alat kontrasepsi secara statistik terdapat hubungan yang bermakna ( $\mathrm{p}<0,05)$. Selain itu antara sikap Wanita Usia Subur (WUS) dengan pemakaian alat kontrasepsi pun terdapat hubungan yang bermakna $(\mathrm{p}<0,05)$. Kesimpulan dari penelitian ini yaitu terdapat hubungan yang signifikan antara pengetahuan dan sikap wanita usia subur dengan pemakaian alat kontrasepsi.
\end{abstract}

Kata kunci: pemakaian alat kontrasepsi, pengetahuan, sikap, wanita usia subur

\begin{abstract}
Prevention of maternal mortality and illness is the main reason for the need for family planning services. The family planning program aims to meet the community's need for family planning services and reproductive health in order to build quality small families. The objective of this study to find out the correlation between the knowledge and the behavior of fertile-aged woman toward the using of contraception.This study used descriptive correlative method with cross sectional approach. The data used in this study was primary data that were collected using questioner to 100 fertile-aged woman. This study also used proportional random sampling technique. The data was analyzed by chi square as a computer software program and presented in the form of frequent distribution. From the result of this study, it is known that the knowledge of fertile-aged woman over contraception was in less category (12\%), the behavior of fertile-aged woman over contraception was in category of unfavorable (43\%), and the fertile-aged woman which did not use contraception counted (17\%). Between knowledge of fertile-aged woman (WUS) and the usage of contraception statistically had a correlation valued ( $p<0,05)$. Furthermore, between attitude of fertile-aged woman and the using of contraception had relationship valued $(p<0,05)$. This research indicates that there is a significant correlation between fertile aged woman knowledge with their behavior toward the using of contraception.
\end{abstract}

Keywords: contraception usage, knowledge, behavior, fertile-aged woman, 


\section{PENDAHULUAN}

Pembangunan kesehatan bertujuan untuk meningkatkan kesadaran, kemauan,dan kemampuan hidup sehat bagi setiap orang agar terwujud derajat kesehatan masyarakat yang setinggi-tinginya. Untuk mewujudkan tujuan tersebut diselenggarakan pembangunan kesehatan yang berkesinambungan, baik oleh pemerintah pusat, provinsi, kabupaten/kota maupun oleh masyarakat termasuk swasta (Dinas Kesehatan Lampung, 2006).

Pembangunan kesehatan diarahkan untuk mempertinggi derajat kesehatan. Indikator yang mempengaruhi derajat kesehatan diantaranya adalah Angka Kematian Ibu (AKI). Menurut Survey Demografi Kesehatan Indonesia tahun 2007 Angka Kematian Ibu di Indonesia berkisar 228/100.000 kelahiran hidup (Dinas Kesehatan, 2007). Kematian ibu umumnya terjadi pada kelompok ibu dengan resiko tinggi sebagai akibat langsung maupun tidak langsung dari kehamilan maupun persalinan (Mochtar, 1998).

Pencegahan kematian dan kesakitan ibu merupakan alasan utama diperlukannya pelayanan Keluarga Berencana (KB) (POGI et all, 2003).Program KB bertujuan untuk memenuhi keperluan masyarakat akan pelayanan KB dan Kesehatan Reproduksi yang berkualitas termasuk upaya menurunkan angka kematian ibu, bayi dan anak serta penanggulangan masalah kesehatan reproduksi dalam rangka membangun keluarga kecil berkualitas (Syarief, 2007).

Hasil Survey Demografi dan Kesehatan Indonesia (SDKI) tahun 2007 menunjukkan sinyal kuat bahwa ledakan kelahiran bayi sangat mungkin terjadi kembali di Indonesia. Menurut hasil survey tersebut, selama tahun 2007 peserta program KB hanya meningkat 1 $\%$ dari 60,3 \% menjadi 61,4\%. Keterlambatan peningkatan jumlah akseptor tersebut dapat menyebabkan pertumbuhan jumlah penduduk Indonesia akan terus meningkat (BKKBN, 2009).

Menurut data dari BPS Kota Bandar Lampung Angka Proyeksi Survey Penduduk Antar Sensus (SUPAS) 2005, Kelurahan Kaliawi merupakan salah satu kelurahan dengan jumlah penduduk terbanyak dan padat di Kecamatan Tanjung Karang Pusat, yaitu berjumlah 13.290 orang dengan kepadatan penduduk di kelurahan ini mencapai $1.845,83$ per $\mathrm{Km}^{2}$. Pentahapan keluarga sejahtera cukup variatif namun untuk keluarga pra sejahtera dikelurahan ini paling banyak diantara kelurahan lain di kecamatan Tanjung karang Pusat (Badan Pusat Statistik, 2008). 
Berdasarkan Keputusan Menteri Kesehatan RI tahun 2004 tentang "Standar Pelayanan Minimal Bidang Kesehatan di Kabupaten/Kota" ditetapkan target minimal untuk cakupan KB aktif adalah 70\% (Profil Dinkes Lampung, 2006). Pada tahun 2008 jumlah WUS di Kota Bandar Lampung sebanyak 138.122, yang menjadi akseptor KB aktif sebanyak 96.641 atau 69,97\%. Untuk wilayah kecamatan Tanjung Karang Pusat jumlah WUS sebanyak 12.885 yang menjadi akseptor KB aktif sebanyak 9.700 atau 75,28 \% (BKKBN, 2007). Data dari Koordinator KB kecamatan Tanjung Karang Pusat untuk kelurahan Kaliawi jumlah WUS nya sebanyak 2100, yang menjadi akseptor KB aktif sebanyak 1.548 akseptor atau 73,7 \% terdiri dari IUD 222 akseptor, MOW 29 akseptor, MOP 5, Kondom 20 akseptor, Implan 114 akseptor, Suntik 591 akseptor, Pil 567 akseptor (Badan Pusat Statistik, 2008).

Melihat data diatas, tidak semua WUS memakai alat kontrasepsi dalam menjarangkan kehamilan dan mengakhiri kesuburan.Hal ini mungkin disebabkan oleh kurangnya informasi yang diperoleh tentang metode kontrasepsi yang tersedia, rendahnya tingkat pendidikan pasangan tersebut dan rendahnya tingkat ekonomi masyarakat dikelurahan tersebut.
Berdasarkan uraian diatas penulis tertarik melakukan penelitian mengenai hubungan pengetahuan dan sikap wanita usia subur(wus) dengan pemakaian alat kontrasepsi.

\section{METODOLOGI}

Desain penelitian ini adalah penelitian Deskriptif Korelasional dengan pendekatan cross sectional. Penelitian dilakukan di kelurahan Kaliawi, kecamatan Tanjung Karang Pusat, kota Bandar Lampung. Waktu penelitian Desember - April 2009.

Populasi pada penelitian ini adalah seluruh Wanita Usia Subur (WUS) di kelurahan Kaliawi sebanyak 2100 orang.Pemilihan sampel pada penelitian ini akan dilakukan secara proportional random sampling. Besarnya sampel yang akan diteliti adalah 96 orang dengan pembagian di LK 01 sebanyak 34 orang, LK 02 sebanyak 38 orang, dan LK 03 sebanyak 24 orang.Data diolah dengan menggunakan program software komputer dan dianalisis menggunakan uji chi square, kemudian disajikan dalam bentuk distribusi frekuensi 


\section{HASIL}

\section{PengetahuanWanitaUsia Subur tentang}

\section{Pemakaian Alat Kontrasepsi}

Tabel 1. Distribusi Frekuensi Tingkat Pengetahuan WUS mengenai alat kontrasepsi

\begin{tabular}{llll}
\hline No. & Pengetahuan & Frekuensi & Persentase \\
\hline 1. & Baik & 57 & $57 \%$ \\
2. & Cukup & 31 & $31 \%$ \\
3. & Kurang & 12 & $12 \%$ \\
\hline & Jumlah & $\mathbf{1 0 0}$ & $\mathbf{1 0 0 \%}$ \\
\hline
\end{tabular}

diketahui bahwa pengetahuan responden mengenai alat kontrasepsi yang termasuk dalam kategori cukup 31 orang (31\%) dan kategori kurang 12 orang ( $12 \%$ ).

\section{Sikap Wanita Usia Subur tentang}

\section{Pemakaian Alat Kontrasepsi}

Tabel 2. Distribusi Frekuensi Sikap WUS mengenai alat kontrasepsi

\begin{tabular}{llll}
\hline No. & JumlahAnak & Frekuensi & Persentase \\
\hline 1. & Positif & 57 & $57 \%$ \\
2. & Negatif & 43 & $43 \%$ \\
\hline & Jumlah & $\mathbf{1 0 0}$ & $\mathbf{1 0 0 \%}$ \\
\hline
\end{tabular}

Berdasarkan tabel 2 terlihat bahwa sebanyak 43 responden ( $43 \%$ ) yang bersikap negatif terhadap alat kontrasepsi.

\section{Pemakaian Alat Kontrasepsi}

Tabel 3. Distribusi frekuensi pemakaian/ konsumsi alat kontrasepsi

\begin{tabular}{llll}
\hline No. & Kategori & Frekuensi & Persentase \\
\hline 1. & $\begin{array}{l}\text { Memakai / } \\
\text { mengkonsumsi } \\
\text { Tidakmemakai / } \\
\text { mengkonsumsi }\end{array}$ & 83 & $83 \%$ \\
\hline Jumlah & 17 & $17 \%$ \\
\hline
\end{tabular}

Berdasarkan tabel 3.terlihat bahwa sebanyak 83 responden ( $83 \%$ ) yang memakai / mengkonsumsi alat kontrasepsi, sedangkan 17 responden (17 \%) tidak memakai/ mengkonsumsi alat kontrasepsi.

\section{Hubungan Antara Pengetahuan Wanita} Usia Subur Dengan Pemakaian Alat

\section{Kontrasepsi}

Tabel 4. Analisis Hubungan Antara Pengetahuan Wanita Usia Subur Dengan Pemakaian Alat Kontrasepsi

\begin{tabular}{llll}
\hline \multirow{2}{*}{ Pengetahuan } & \multicolumn{3}{c}{ Pemakaian / } \\
& konsumsialatkontrasepsi & \\
\cline { 2 - 3 } & Tidak & Ya & \\
\hline Baik & 4 & 53 & 57 \\
Cukup & 10 & 21 & 31 \\
Kurang & 3 & 9 & 12 \\
\hline Total & $\mathbf{1 7}$ & $\mathbf{8 3}$ & $\mathbf{1 0 0}$ \\
\hline
\end{tabular}

Berdasarkan tabel 4 tampak bahwa setelah dilakukan penghitungan secara statistic dengan uji chi square, diperoleh suatu kesimpulan bahwa terdapat hubungan antara Pengetahuan Wanita Usia Subur Dengan Pemakaian Alat Kontrasepsi. Hal ini dapat dilihat dari nilai $\chi^{2}$ hitung $=9,685>$ $\chi^{2}$ tabel $=5,99$ dan nilai p_value $^{2}=0,008<$ $0,05)$. 
Hubungan Antara Sikap Wanita Usia Subur Dengan Pemakaian Alat Kontrasepsi

Tabel 5. Hubungan Antara Sikap Wanita Usia Subur Dengan Pemakaian Alat Kontrasepsi

\begin{tabular}{llll}
\hline Sikap & \multicolumn{2}{l}{ Pemakaianalatkontrasepsi } & Total \\
\cline { 2 - 3 } & Tidak & Pakai & \\
\hline Positif & 4 & 53 & 57 \\
Negatif & 13 & 30 & 43 \\
\hline Total & $\mathbf{1 7}$ & $\mathbf{8 3}$ & $\mathbf{1 0 0}$ \\
\hline
\end{tabular}

Berdasarkan hasil uji chi-square pada tabel 5 menunjukkan bahwa tidak terdapat perbedaan pengetahuan ibu terdapat hubungan antara Sikap Wanita Usia Subur Dengan Pemakaian Alat Kontrasepsi. Hal ini dapat dilihat dari nilai $\chi^{2}$ hitung $=9,362>$ $\chi^{2}$ tabel $=3,84$ dan nilai p_value $=0,002<$ $0,05)$.

\section{PEMBAHASAN}

Hasil penelitian ini menunjukkan bahwa pengetahuan Wanita Usia Subur (WUS) dengan kategori baik $57 \%$, kategori cukup $31 \%$ dan kategori kurang $12 \%$. Dari data tersebut terlihat bahwa Wanita Usia Subur (WUS) yang mempunyai pengetahuan cukup dan kurang masih banyak.Hal ini mengindikasikan bahwa pengetahuan mereka tentang kontrasepsi masih kurang.

Faktor-faktor yang mempengaruhi pengetahuan seseorang antara lain; Pertama faktor usia, usia dapat mempengaruhi seseorang dalam kesiapan belajar dan menerima informasi baru. Kedua pendidikan, dimana pendidikan mempengaruhi proses belajar. Makin tinggi pendidikan seseorang, makin mudah orang tersebut menerima informasi. Ketiga faktor pekerjaan, orang yang bekerja akan lebih banyak teman dan tempat untuk bertukar pengalaman dan informasi sehingga pengetahuannya pun bertambah. Semakin banyak mendengar tentang informasi tersebut maka pengetahuannya akan semakin baik (Notoatmodjo, 2007). Perilaku yang didasari oleh pengetahuan akan lebih baik dari pada perilaku yang tidak didasari oleh pengetahuan.

Hasil penelitian menunjukkan bahwa Wanita Usia Subur (WUS) yang memiliki sikap positif terhadap pemakaian alat kontrasepsi sebanyak 57 orang (57\%) sedangkan sikap negatif sebanyak 43 orang (43\%). Hal ini mengindikasikan bahwa dalam pelaksanaan KB masih banyak Wanita Usia Subur yang acuh tak acuh terhadap Keluarga Berencana. Baik suami maupun istri bertanggung jawab terhadap keluarga dalam menjaga dan meningkatkan kesehatan reproduksi pasangannya.Khususnya wanita dimana ia adalah faktor yang sangat penting dalam mewariskan status kesehatan kepada anakanak mereka (Notoatmodjo, 2007). 
Hasil penelitian menunjukkan bahwa sebagian besar WUS memakai alat kontrasepsi. Berdasarkan hasil penelitian yang telah dilakukan bahwa WUS yang tidak memakai alat kontrasepsi dikarenakan oleh keinginan untuk mempunyai anak lagi, sedang hamil, mempunyai suatu penyakit, belum punya anak sama sekali dan sebagainya.

Setelah seseorang mengetahui stimulus atau objek kesehatan, kemudian mengadakan penilaian atau pendapat terhadap apa yang diketahui, proses selanjutnya diharapkan ia akan melaksanakan atau mempraktikkan apa yang diketahui atau disikapinya (dinilai baik) (Notoatmodjo, 2007).

Hasil penelitian menunjukkan bahwa terdapat hubungan antara Pengetahuan Wanita Usia Subur Dengan Pemakaian Alat Kontrasepsi. Hal ini dapat dilihat dari nilai $\chi^{2}$ hitung $=9,685>\chi^{2}$ tabel $=5,99$ dan nilai p_value $=0,008<0,05)$. Hal ini sesuai dengan teori yang menjelaskan bahwa pengetahuan merupakan hasil dari tahu, dan terjadi setelah orang melakukan penginderaan terhadap suatu objek tertentu. Untuk itu pemberian informasi kepada Wanita Usia Subur (WUS) tentang pemakaian alat kontrasepsi akan mempengaruhi pengetahuan Wanita Usia Subur (WUS), sehingga pengetahuan WUS tentang alat kontrasepsi akan menjadi lebih baik. Dengan demikian, kemungkinan WUS untuk memakai alat kontrasepsi akan lebih meningkat.

Hasil penelitian menunjukkan bahwa terdapat hubungan antara Sikap Wanita Usia Subur (WUS) Dengan Pemakaian Alat Kontrasepsi. Hal ini dapat dilihat dari nilai $\chi^{2}$ hitung $=9,362>\chi^{2}$ tabel $=3,84$ dan nilai p_value $=0,000<0,05)$.

Sikap merupakan reaksi atau respon yang masih tertutup dari seseorang terhadap suatu stimulus atau objek. Perwujudan sikap itu tidak dapat langsung dilihat, tetapi hanya dapat ditaksirkan terlebih dahulu dari perilaku yang tertutup.

\section{KESIMPULAN}

Berdasarkan hasil penelitian dapat disimpulkan bahwa:

a. Pengetahuan Wanita Usia Subur (WUS) tentang alat kontrasepsi, termasuk dalam kategori cukup yaitu sebanyak 31 orang (31\%) dan kategori kurang sebanyak 12 orang (12\%).

b. Sikap wanita usia subur (WUS) terhadap alat kontrasepsi memiliki sikap positif sebanyak 57 orang (57 \%), sedangkan yang bersikap negatif sebanyak 43 orang (43\%).

c. Terdapat hubungan yang bermakna antara pengetahuan wanita usia subur 
(WUS) dengan pemakaian alat

kontrasepsi.

d. Terdapat hubungan yang bermakna antara sikap wanita usia subur (WUS) dengan pemakaian alat kontrasepsi.

\section{KEPUSTAKAAN}

Badan Pusat Statistik. (2008). Kecamatan Tanjung Karang Pusat DalamAngka 2008. Bandar Lampung. Hal 3-52.

BKKBN.(2007). Rapat Kerja Daerah (RAKERDA) Program KB Nasional Provinsi Lampung. Bandar Lampung

BKKBN.(2009). WaspadaiAncaman Baby Booming; (diakses 29 Januari 2009).http://www.nkknm.go.id

Dinas Kesehatan Lampung. (2006). Profil Kesehatan Propinsi Lampung tahun 2006.Hal 1,9,35,60.

Dinas Kesehatan. (2007). Profil Kesehatan Reproduksi Indonesia. (2007). Jakarta Mochtar R. (1998). Sinopsis Obstetri. EGC Notoatmodjo.(2007). Promosi Kesehatan dan Ilmu Perilaku.RinekaCipta. Hal 139144, 178.

POGI, IDI, IBI, PKBI, PKMI, BKKBN et al. (2003).BukuPanduanPraktisPelayanan Kontrasepsi. Tridasa Printer. Hal 79-82 Syarief, Sugiri. (2007). Seminar Pelayanan Keluarga Berencana dan Kesehatan Reproduksi. Jakarta 